\title{
SELECTED RELIABLE INDICATORS OF SUSTAINABLE LAND MANAGEMENT (SLM) IN THE EUROPEAN UNION
}

\section{Zsuzsanna Tóth-Naár*, Tamás Antal Naár, Ádám Pál Sőreg, Sergey Vinogradov}

Szent Istvan University, Institute of Economics, Law and Methodology, Gödöllő, Hungary

The concept of sustainability and the feasibility options have been discussed in specialized literature sources for about three decades only. Sustainable development has several definitions; it is defined both in narrow and wider sense. The definition of sustainability is regarded inevitable because the sustainability of agriculture can be interpreted only within this fixed conceptual framework. Our study primarily deals with issues of sustainability in farming practices being specific to countries and regions of the European Union. In frames of the current research we provide the analysis of the ability to produce value added within agricultural sector, the intensity of farming, the non-renewable external input use, farm structure as well as the European-level relations being directed towards the preservation of land productivity.

Keywords: agricultural economics, sustainable land management, indicators, natural resource economics

\section{$1 \quad$ Introduction}

Sustainable development is a versatile and dynamic concept, which should primarily be regarded as a transformation process, closely related to local needs, conditions and priorities (Mészáros, 2007). H. Daly argues that sustainable development is nothing else than achieving permanent social welfare without overburdening the ecological carrying capacity of our environment (Daly, 1991). There has been a generally accepted view that sustainable development is based on three basic pillars, namely on environmental, economic and social pillars. As for Hungarian experts, Csete (2005), Bulla et al. (2006) and Magda $(2010,2013)$ have dealt with these dimensions of sustainability in depth. The Global Sustainable Competitiveness Index (GSCl) calculated by SolAbility (2016) ranks 180 countries against 109 quantitative sustainability indicators grouped in 5 pillars: natural capital, resource intensity, social capital, intellectual capital, and governance capital.

The importance of the environmental pillar (natural capital, resource intensity) comes from the fact that environment and ecosystems are inevitably necessary for our survival and meeting our needs in the long run. Producing food is impossible without the vital elements, i.e. water and soil; there is no life without oxygen; therefore, environment is a vital prerequisite for all of us. For the definition of the concept it cannot be disregarded that the natural resources are finite (Schumacher, 1989; Hardin, 1993; Daly, 1996; Meadows et al., 2004; Speth, 2008; Magda, 2012). Human consumption had already exceeded the acceptable limits by the end of the 20th century. The three pillars of sustainability, their intertwining and interdependence presume problem solving beyond geographical and institutional boundaries (Daly, 1990 quoted by Lisányi, 2011). Daly (1990) who is an ecological economist defines sustainable development as follows: "Sustainable development means to achieve infinite social welfare without expanding beyond the ecological carrying capacity. Growth means that we are getting bigger and development means that we are getting better."

On the basis of a comprehensive database the present paper analyses the aspects of farming practices in the agricultural sector of the EU-28 countries in terms of sustainability.

\section{Analysing sustainability of agricultural practices in the EU member countries}

The regional NUTS- 2 breakdown spreadsheets of Eurostat provide information about outputs and input use, added value producing ability as well as the environmental impacts of agriculture. In case of some countries - Slovenia, the Czech Republic and Belgium - the Eurostat data had to be complemented with data published by national statistical offices in accordance with the statistical nomenclature of the European Union because - for unknown reasons - the inevitable information regarding these countries was not included in the tables compiled by Eurostat.

Out of the variables describing agricultural land use and farm structure, the parameters involved in the examination included the ratio of area utilized for agricultural activities at regional level and the total area of a statistical region (1); ratio of arable land within the area utilized for agricultural purposes; (2) average farm size (3) and proportion of farms operating on more than 100 hectares (4). These variables can essentially describe the size of the area and the farm estate structure used by the local agriculture within the given NUTS-2 region.

The volume of livestock production activities can be measured at regional level by calculating the livestock density per 100 hectare parameter (5) while the value creating capacity of agriculture, the efficiency of resource utilization and the sustainability of farming can be measured with help of the following variables: produced added value in the percentage of gross output (6), added value produced by using one euro external non-renewable input (7) and intensity of soil erosion per hectare caused by water (8).

In terms of agricultural inputs, arable land can be regarded as one of the most important as well as renewable resources. It is essential to consider, however, that the soil layer is more of a conditionally renewable resource, which requires that proper agricultural practices are in place. Farming, which is inappropriate from the aspect of preserving the fertility of soil, will lead to deterioration of soil structure, decreasing nutrient providing capacity and soil erosion caused by water and wind. While soil structure or poor nutrient supply can be relatively easily improved under the current technological conditions, the negative impacts of thinning topsoil can affect the efficiency of agricultural production for several decades or even a century, thus deteriorating the standard of living of future generations. Considering the aforementioned, one of the main elements of examining sustainability in agricultural practices should be the examination of applied cultivation 
methods, farm structure, farming sectors, etc. in terms of their ability to prevent the expansion of soil erosion beyond acceptable levels (Zachar, 1982). The categories of soil erosion classified by intensity are presented in Table 1.

Considering temperature, length of the vegetation period and precipitation, the pace of soil formation in agricultural areas of the European Union is $0.25-1.5 \mathrm{~mm} /$ year. The former data are typical in the areas with the most adverse conditions (cold and/or dry), while the latter describes the most advantaged, warm areas, where there is enough precipitation throughout the year. The estimated annual new soil layer formation in most parts of agricultural areas is 0.5-1.0 mm/year (FA0, 2017).

On the basis of the above, there are altogether 65 statistical regions within the European Union which can be classified as regions with considerable or severe soil erosion issues. Due to inappropriate agricultural practices, the pace of soil erosion in these regions reaches or surpasses the regeneration ability of soils which means sustainability risks in the agricultural sector for several decades or even centuries ahead.

More than three quarters of regions with considerable or severe soil erosion can be found in the Southern Europe. There are 20 regions with this issue in Italy, 9 regions in Spain, 10 regions in Greece, 5 regions in Southern France, 3 regions in Portugal, 1 region on the Croatian seaside and 1 region in Malta. Soil erosion is also very intensive in lands of six mountainous areas of Austria and in Slovenia. There are 4 similar regions in the United Kingdom in the rainy and mountainous Wales and Scotland. Regarding the Eastern and the Central Europe, there are areas moderately or heavily affected by soil erosion in the Southern Danubia in Hungary, in the Little Poland and in 3 regions in the central and the northern part of Romania.

The average annual degree of soil erosion in the 177 regions which are not listed above is typically below the limit set by the natural

Table 1 Classification of soil erosion according to its intensity

\begin{tabular}{|c|c|c|c|c|}
\hline \multirow[t]{2}{*}{ Category } & \multicolumn{2}{|c|}{ Intensity of soil erosion } & \multirow[t]{2}{*}{ Description } & \multirow[t]{2}{*}{ No of NUTS-2 regions } \\
\hline & $\mathrm{mm} / \mathrm{ha} /$ year & t/ha/year & & \\
\hline 1 & $<0.04$ & $<0.5$ & insignificant soil erosion & (41) \\
\hline 2 & $0.04 \ldots 0.25$ & $0.6 \ldots 3.0$ & weak erosion & (136) \\
\hline 3 & $0.26 \ldots 1.0$ & $3.1 \ldots 12$ & considerable erosion & (59) \\
\hline 4 & $1.01 \ldots 4.0$ & $12.1 \ldots 50$ & severe erosion & (6) \\
\hline 5 & $4.01 \ldots 16.0$ & $50.1 \ldots 200$ & very severe erosion & - \\
\hline 6 & $16.0<$ & $200<$ & catastrophic erosion & - \\
\hline
\end{tabular}

Source: own construction on the basis of Zachar (1982), EUROSTAT (2017) regeneration ability of soils, therefore from this aspect the agricultural activities in these regions do not endanger fertility of soils in the long run.

The population density in the area (9) can be considered as an independent factor from the local agricultural activity, though affecting it, primarily with an impact on the scarcity of land as a resource. Since there is almost a thousandfold difference between the population density in the most and the least densely populated areas of the European Union, it is worth classifying the regions according to this natural logarithm - In (population density).

The external, non-renewable agricultural inputs include the value of energy consumption per hectare, fertilizer use, pesticides and additional technical investments (machinery and facilities). These inputs are used by modern agriculture in great volumes, but it is unable to produce them and, therefore, these are characterized as external. It is important to note that major part of these inputs - including energy consumption or the conditions of producing the required quantity of fertilizers - come from nonrenewable sources. The intensity of agricultural activities and the sustainability of farming practice can be characterized by a parameter, namely the value which can be created on a given area with the use of one euro of external input. The higher is the created added value compared to the external inputs used, the more favourable evaluation can be given to the farming practice of the given region in terms of sustainability.

The presented data are available at NUTS2 regional level for 2013; the only exception is the estimated degree of soil erosion per hectare, which was put in the Eurostat spreadsheet as the result of a survey carried out in the whole area of the European Union in 2012. The data on the added value, gross output and external inputs from 2013 are missing in case of some member countries; therefore, the data from either 2012 or 2014 were consistently used for specifying the ratios on additional bases.

\section{Cluster analysis at regional level}

By dividing the 28 countries of the European Union into 242 statistical regions, K-means cluster analysis helped to examine the regional differences between the applied agricultural practices and the sustainability aspects.

The statistical regions were divided into 6 separate clusters: the first main group included the basically extensive regions, which produce low value per hectare and use only a few external inputs. On the basis of the available data, more than a half of the regions in the EU-28 belong here. These regions can be described with low population density in European terms and duality in the field of agricultural farm structure: the territorial share of large-scale farms operating on more than a 100 -hectare area is almost $50 \%$, but due to the large number of private farms which operate on a few hectares, the average farm size is only around 24 hectares (Table 2). The ratio of arable land within the area used for agricultural purposes is $57.6 \%$, the other area is grassland and, to a smaller extent, there is also land used for horticultural production. The low input use, almost $50 \%$ of added value producing ability and the very favourable 2.64 $€$ added value per one euro of external input slightly contradicts to the fact that the average degree of soil erosion is the highest in this area within the 6 clusters. This latter is related to the fact that most of the regions of the Southern European countries, which are affected by severe soil erosion due to inappropriate agricultural practices but deal with less intensive farming, belong to this main group.

The second main group includes 55 regions, which can be characterized with semi-intensive farming. These regions are marked by higher population density; relative dominance of livestock sector; almost twice as big, more than 40-hectare farm size, but weaker added value producing capacity compared to the external inputs utilized and the gross output.

The third group is formed by those regions altogether 45 regions - where almost exclusively large-scale field crop production is conducted. The average farm size is more than 120 hectares; the share of farms with more than 100 hectares is $84.4 \%$ from the cultivated areas. The livestock density is low and the population density is similar to that of the second group.

The fourth, fifth and sixth main groups consist of 8-4-2 regions, which can be described with intensive and extremely intensive farming. 
Table 2 Results of K-means cluster analysis according to NUTS-2 regions

\begin{tabular}{|c|c|c|c|c|c|c|c|}
\hline & & CL1 & CL2 & CL3 & CL4 & CL5 & CL6 \\
\hline & & Extensive & Semi-intensive & Large-scale field crop production & Intensive-1 & Intensive-2 & Intensive-3 \\
\hline & Population density (head/km2) & 105.3 & 177.0 & 179.8 & 355.7 & 418.6 & 497.2 \\
\hline var01 & LN(population density) & 4.657 & 5.176 & 5.192 & 5.874 & 6.037 & 6.209 \\
\hline var02 & average farm size (ha) & 24.4 & 41.3 & 128.6 & 26.1 & 23.1 & 21.0 \\
\hline var03 & ratio of farms above 100 ha (\%) & 44.6 & 39.6 & 84.4 & 19.4 & 10.0 & 14.2 \\
\hline var04 & agricultural area (\%) & 37.1 & 47.9 & 56.6 & 42.1 & 50.1 & 46.5 \\
\hline var05 & out of this: field crop (\%) & 57.6 & 48.4 & 67.3 & 57.4 & 53.4 & 78.6 \\
\hline var06 & animal stock per 100 ha & 48 & 135 & 56 & 296 & 539 & 730 \\
\hline var07 & intensity of soil erosion (t/ha) & 3.43 & 2.23 & 1.24 & 2.72 & 0.39 & 0.48 \\
\hline var08 & added value / output (\%) & 45.6 & 37.3 & 36.6 & 43.3 & 46.7 & 27.9 \\
\hline var09 & added value / ext.input & 2.64 & 2.33 & 1.53 & 3.15 & 3.01 & 1.54 \\
\hline
\end{tabular}

Source: own construction on the basis of EUROSTAT (2017) and own calculations
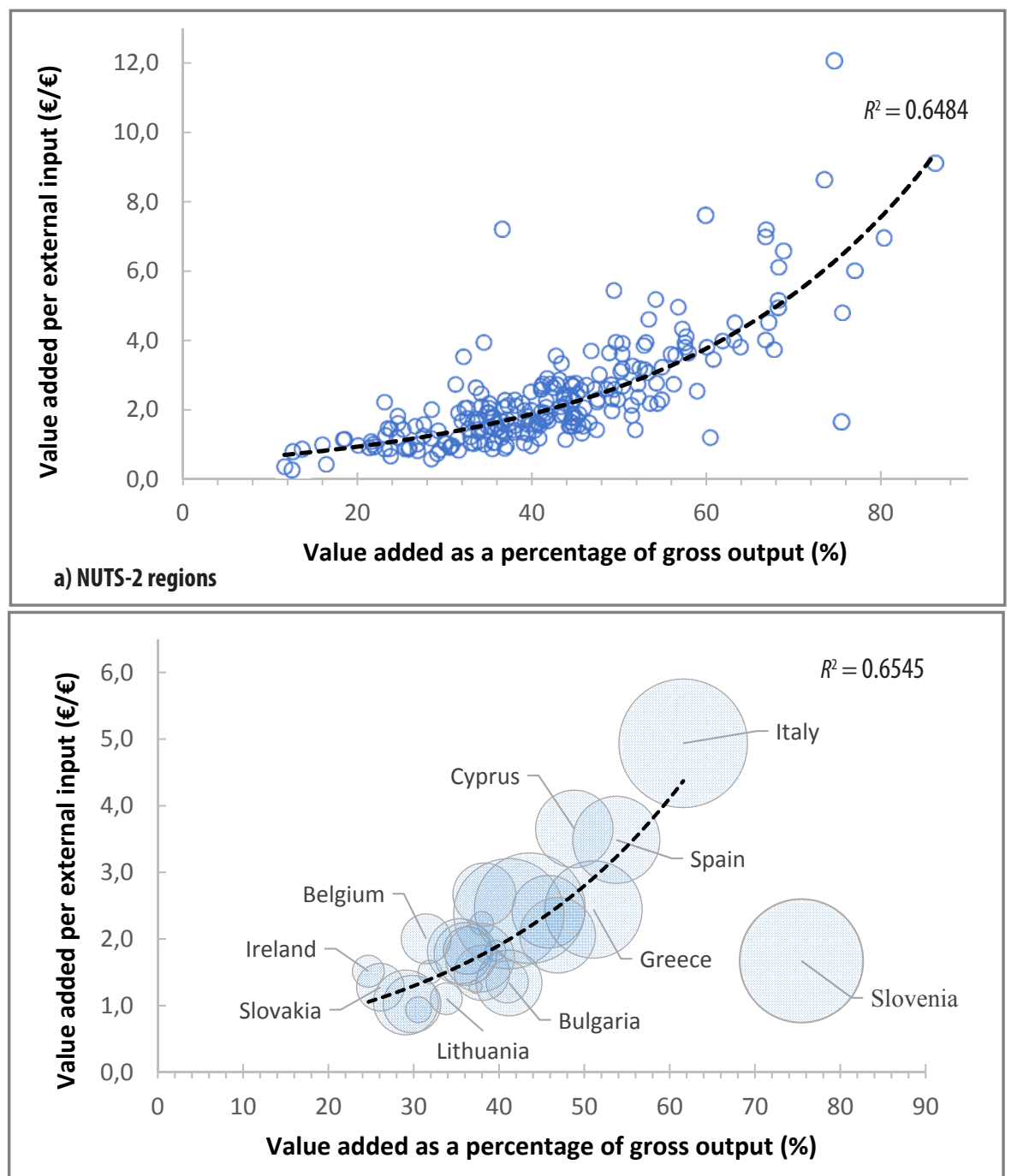

b) countries (diameter circle: national average of exposure to soil erosion)s

Figure 1 Relation between agricultural gross output, added value and external input use in the 28 countries of the European Union

Source:own construction on the basis of EUROSTAT (2017) and own calculation
Most of these regions can be found in Belgium and the Netherlands, but Lombardi in Italy and Catalonia in Spain within the Southern Europe also belong here. One of the features of regions dealing with intensive farming is high population density, which makes arable land very scarce as a resource and thus very expensive within a region. The high land price per hectare results into the situation when the primary way of developing agricultural enterprises is not territorial expansion but rather the growth of farming intensity. There are less large-scale farms in the regions dealing with intensive farming, and the livestock density is very high. The external input use is outstanding compared to other regions, especially the value of energy, fertilizer and pesticide inputs per hectare. The intensive areas, however, are not able to produce significantly greater value by using one euro of external input than the regions using intensive farming practices. This leads to the conclusion that local conditions play greater role in the development of intensive farming practices all over Europe than economic considerations, e.g. higher efficiency in utilizing resources and higher added value producing capacity.

Both in regional and national comparisons, there is a significant exponential correlation characterized with $64.8 \%$ and $65.4 \%$ determination - between the added value producing capacity measured in relation to agricultural gross output and the added value created by using one euro of external input. The added value in the percentage of gross output is extremely low in those regions, which belong to the cluster 3 and deal with field crop production in large-scale farming structure, while in the 
Southern Europe - Italy, Spain, Greece and Slovenia - it is mostly above 60\% (Figure 1).

\section{Conclusions}

The European Union (formerly the European Community) has encouraged wider and more comprehensive definition of economic and social development for many decades. The technologies used in economic activities are more and more complex, and consequently the environmental and sustainability related risks, as well as the transnational, global challenges have been increasing in almost all the sectors (Gordos and Bartha, 2002).

The agricultural sector utilises one of the most important natural resources, arable land, and it can be regarded as a sector of strategic importance in all the countries from the aspect of food supply safety. As it was indicated above, arable land is a renewable resource, but this favourable feature of land can prevail only in case of properly selected cultivation methods and farming practice. The current productivity of farming depends on - besides land assets - a number of external inputs, e.g. energy, fertilizers, pesticides, etc., which are mostly produced from non-renewable sources, therefore, their efficient use is a key issue in terms of sustainability.

The regions of Europe can be divided into different separate groups on the basis of the special features characterizing the agricultural production. On more than a half of the area of the European Union, a relatively extensive agricultural cultivation is going on, which can be regarded as advantageous in terms of sustainability due to the related low non-renewable input use, $45-50$ per cent added value producing capacity and the $2.64 €$ added value per one euro of external input. It slightly contradicts to the fact that the exposure to soil erosion is the highest here because this includes most of the regions in the Southern European countries, where less intensive farming is pursued, although far from ideal farming practices in terms of preserving the fertile soil layer.

Field crop production is dominant in the East German provinces, the northern part of France, the Czech Republic and Slovakia, as well as the eastern part of the United Kingdom. The low added value producing capacity and the imbalance of relative weight of field crop production and livestock production may cause problems but the external input use per hectare will remain low.

One of the features of areas affected by intensive farming is high population density and, consequently, high land prices per hectare. The external input use is very high here compared to other regions, especially the value of energy, fertilizers and pesticide inputs per hectare. Compared to the regions dealing with extensive farming, the intensive areas are not able to produce significantly greater value with the use of one euro of external input in spite of the strong concentration of production. It can be presumed that the local land market - affected by high population density - is behind the intensive farming practice, and not some economic considerations or higher productivity, which could be achieved with these.

\section{References}

BULLA, M. - TAMÁS, P. 2006. Sustainable Development in Hungary - Future Scenarios (in Hungarian). Budapest : Új Mandátum Könyvkiadó, 2006, 512 p.

CSETE, L. 2003. Sustainable agriculture, sustainable rural areas (in Hungarian). In A Falu, 2003, no. 4, pp. 39-43.

DALY, H. E. 1990. Sustainable Growth: An Impossibility Theorem. Rome, Development 3/4, 1990.

DALY, H.E. 1991. Steady-state economics. Washington, D.C. : Island Press, 1991.
DALY, H. E. 1996. Beyond growth: The economics of sustainable development. Boston : Beacon, 1996, $253 \mathrm{p}$.

EUROSTAT. 2017. Regional statistics by NUTS classification.

RETRIEVED from: http://ec.europa.eu/eurostat/web/regions/data/database

FA0. 2017. Soil erosion and loss of productivity. Agro-ecological land Resources Assessment for agricultural Development Planning, Chapter Five, 2017.

RETRIEVED from: http://www.fao.org/docrep/009/t0733e/T0733E06.htm

GORDOS, Á. - BARTHA, P. 2002. The process leading to the adoption of the goals and strategic foundations for sustainable development in the European Union (in Hungarian). Budapest : Sustainable Development Commission, 2002.

HARDIN, G. 1993. Living within limits: Ecology, economics and population taboos. New York: Oxford University Press, 1993, $25 \mathrm{p}$.

LISÁNYI, E. - BEKE, J. 2011. The criteria system and results of sustainable agriculture in Denmark and Hungary. PhD Thesis : Gödöllő : Szent István University, 2011, 150 p.

MAGDA, R. 2010. Land Use and Sustainability (in Hungarian). In Gazdálkodás, vol. 54, 2010, no. 2, no. pp. 160-168.

MAGDA, R. 2012. Economic questions of land usage - scarcity, sustainability. In APSTRACT, 2012, no. 3-4, pp. 43-47.

MAGDA, R. 2013. Difficulties in sustainability and land utilisation. In Visegrad Journal on Bioeconomy and Sustainable Development, vol. 2, 2013, no. 1, p. 15-18.

MEADOWS, D. - RANDERS, J. - MEADOWS, D. 2004. Limits to growth: The 30-year update. White River Junction, Chelsea Green : VT, 2004, 205 p.

MÉSZÁROS, A. 2007. Indicators of sustainable energy management in the context of environmental programs (In Hungarian). In Hungarian Statistical Review, vol. 85, 2007, no. 7, pp. 602-622.

SCHUMACHER, E. F. 1989. Small is beautiful: Economics as if people mattered (Reissued ed.). New York : Harper Perennial, 1989, $288 \mathrm{p}$.

SOLABILITY. 2016. The Global Sustainable Competitiveness Index 2016. $5^{\text {th }}$ ed., 2016, $58 \mathrm{p}$.

SPETH, J. G. 2008. The bridge at the end of the world: Capitalism, the environment, and crossing from crisis to sustainability. New Haven, CT : Yale University Press, 2008, $320 \mathrm{p}$.

ZACHAR, D. 1982. Soil Erosion. Developments in Soil Science 10. Amsterdam : Elsevier Scientific Publishing Company, $547 \mathrm{p}$.

\section{Contact address}

Zsuzsanna Tóth-Naár PhD, associate professor, Szent Istvan University, Institute of Economics, Law and Methodology, Gödöllö, Páter Károly u. 1, 2100, Hungary,

甶 +3628522 000, e-mail: toth.zsuzsanna@gtk.szie.hu 